Yet the difference between adequate and inadequate treatment in this disease may mean the difference between a useful and a useless citizen. In 1924, owing to the diminution in contagious eye diseases in the Metropolitan school district, it was found practicable to devote some space to cases of interstitial keratitis at White Oak, Swanley. Mr. Treacher Collins, Consulting Surgeon to the Hospital since its start as a trachoma school in 1903, states in the Children's Section of the Metropolitan Asylums' Board Annual Report for 1925-1926, that: "the result has proved eminently satisfactory. Twenty-four new cases were admitted and nineteen were discharged. In these latter the inflammation had entirely subsided without, in any case, leading to the incurable blindness which frequently ensues when treatment is neglected or inefficiently applied." He further adds that if the exceptional advantages which White Oak now offers for dealing with this distressing class of case were more generally known many more cases would be sent there for treatment. We trust that our readers in the Metropolitan area will bear this recommendation in mind.

The institutional treatment of trachoma and phlyctenular conjunctivitis in children has proved so eminently successful that its extension to cases of interstitial keratitis is to be heartily welcomed. The opportunities at present afforded are meagre considering the number of cases, especially as regards phlyctenular disease. Nothing succeeds like success and we confidently hope that even greater facilities may be afforded in the future.

\title{
ABSTRACTS
}

\section{I.-ANATOMY AND PHYSIOLOGY}

(1) Dejean, $\mathrm{Ch}$.-Anatomical and embryological study on the mammalian hyaloid; its role in the formation of the ocular media, its limits and structure. (Étude anatomique et embryologique sur la membrane hyaloïde de l'oeil des mammifères. Son role dans la formation des milieux de l'oeil, ses limites, sa structure.) Arch. d'Ophtal., Vol. XLIII, No. 5, May, 1926.

(1) In this paper, which is a continuation of Dejean's previous work on the origin of the vitreous, the question of the staining reactions of the various parts of the developing eye is discussed. An attempt is made to settle the perennial arguments as to the mesodermal or ectodermal nature of the vitreous and the presence or absence of a hyaloid membrane. The paper is divided into sections as follows : 
(1) Proofs of the existence of the hyaloid membrane. Macroscopic investigations on fresh eyes in various mammals are described, and also microscopic appearances, stress being laid on the necessity for perfectly tangential sections.

(2) Origin and development of the hyaloid membrane. This is the most important section of the paper. In it Dejean describes his findings in early embryos of rabbit, sheep, and other vertebrates. He employed differential stains designed to show the presence or absence of collagen, and he takes the presence of the particular colouration involved to indicate the mesodermal origin of the tissue so stained. In all cases he found a surface membrane on the developing inner layer of the optic cup which gave a collagen reaction. This membrane was continuous with a similar one on the surface of the lens vesicle and as lens and retina separated these membranes widened, became less dense and formed the primitive vitreous. This he therefore considers to be mesodermal in origin. He states that he was able to distinguish, in older embryos, between remains of this membrane-the hyaloid proper-and the internal limiting membrane of the retina. $\mathrm{He}$ traces the hyaloid membrane anteriorly on to the ciliary body and observes the development of the zonule fibres from it in this region. As development proceeds a secondary vitreous is formed from the membrane in the region of the retina, which displaces the primitive vascular vitreous towards the lens and towards the centre of the eye. The line of contact between primitive and secondary vitreous undergoes condensation and forms an "intervitreous" limiting membrane which lines the patellar fossa and the canal of Cloquet, and separates the vitreous proper from the zonule region. The anatomical arrangements are described in detail, and three membranes are recognized:

(a) The hyaloid membrane proper, which lines the retina as far forwards as the ora serrata, to which it is strongly adherent.

(b) The limiting membrane of the ciliary region, which is the anterior portion of the hyaloid proper, and covers the ciliary processes and the anterior surface of the zonule.

(c) The intervitreous membrane which runs from the ora serrata to the lens and turns backwards to line the canal of Cloquet.

(3) The anatomical peculiarities of the adult hyaloid and the consequences from the point of view of operation. This section deals with the points of attachment and the general disposition of these membranes in the adult and discusses the importance of the intervitreous membrane in intracapsular extraction.

(4) A short section on the structure of the hyaloid membrane. This deals with the adhesion of the vitreous fibrils to the membrane and its condensed nature.

IDA C. MANN. 
(2) Dejean, C. (Paris). - On the formation of the structure of the vitreous in the eye of vertebrates. (Sur la formation des milieux figurés de l'oeil des vertébrés.) Arch. d'Ophtal., Vol. XLI, p. 659, 1924.

(2) In this paper Dejean deals with the much disputed question of the origin of the vitreous. He summarizes the views of previous observers, dealing in the first place with the older view that the surface ectoderm of the head is originally separated from the optic outgrowth by mesoderm, which therefore becomes compressed between the two as they approximate. He shows that (as is now accepted by most anatomists) in reality the optic outgrowth can be recognized as a pit on the floor of the wide open neural plate while this is still directly continuous with the surface ectoderm, and that at this stage the two ectoderms are in direct contact, no mesoderm intervening. He considers the alternative views that :

(1) There is an intermediate layer of connective tissue separating lens plate from optic vesicle and that this layer forms the vitreous (Kölliker).

(2) Into a mesodermal separating layer grow ectodermal fibrils from the lens vesicle and the retina (van Pee), and that

(3) the vitreous is entirely ectodermal and is derived from filaments which directly connect lens and retina (Laguesse, v. Szili, Mawas and Magitot).

He has himself studied embryos of mammals, birds, reptiles, and fish. He considers that the small isolated cells found between the lens and retina in early stages are entirely vaso-formative in nature. They occur in much greater number in animals which have a large and well-developed hyaloid system. The more or less homogeneous medium in which they are embedded gives the staining reactions of collagen very strongly at a time when the rest of the mesodermal connecting substance is in the stage of pre-collagen. He considers that the appearance of protoplasmic bridges between lens and retina is chiefly an artefact due to shrinkage and vacuolation of the cells and that the primitive vitreous is developed from the thickened basement membranes of lens vesicle and retina. He considers that a secondary vitreous body develops later in mammals, from the retinal basement membrane only, and displaces the primitive vitreous towards Cloquet's canal and the back of the lens, and towards the ciliary region (where it forms the zonule).

He ends by stating that chemical researches on the adult vitreous show it to resemble chemically other connective tissue substances, but to contain a higher percentage of mucin. It does not show the reactions of neuroglia, nor does it contain elastin or gelatin, 
It presents the characters of embryonic connective tissue. The vitreous is therefore a true connective tissue substance specialized for a definite function, by arrest at an embryonic stage.

IDA C. ManN.

(3) Halbertsma, K. T. A. (Leyden).-Two cases of microphthalmos with orbital cyst. (Deux cas de microphtalmos avec kyste orbitaire.) Arch. d'Ophtal., November, 1925.

(3) Halbertsma in this paper has had two specimens of microphthalmos of which he has made an exhaustive study. In his first case the eye was not removed until the patient was aged 19 years; the measurements of the globe were $12 \times 10 \times 10 \mathrm{~mm}$., and those of the attached cyst $36 \times 20 \times 10 \mathrm{~mm}$. The second specimen was obtained from a child, aged 9 weeks. In each case the fellow eye was normal. The cases appear to be fairly typical and do not present any unusual features. The anatomical and histological characters are described in full detail and form interesting reading. The author has evidently expended much time and care in the preparation of microscopic sections, but the reproduction of his microphotographs are so poor that few of them are of much help to the reader. Halbertsma discusses the pathogenesis of this developmental anomaly at considerable length but his views cannot be adequately represented in an abstract. Those interested will do well to consult the original.

J. B. LAWFORD.

\section{(4) Graves, Basil (Liverpool).-Change of tension on the lens capsules during accommodation and under the influence of various drugs. Brit. Med. Jl., January 9, 1926.}

(4) In this paper, which was first read before the American Ophthalmological Society, Graves describes the slit-lamp findings in a very interesting case in which the entire lens substance had undergone absorption, leaving the lens capsule intact save for a minute hole, and with clear media. The original injury was probably due to a foreign body which was still to be seen as a tiny brown spherical object at the bottom of the anterior chamber. The eye with a $+14 \mathrm{D}$. sph. had a visual acuity of $6 / 5$. Graves made numerous observations on the effects of accommodation and drugs on the capsule. The posterior part altered more in the nature of relaxation than the anterior part. He sums up as follows: "The behaviour of these capsules shows that one mechanical result in the process of accommodation consists in a relaxation of their state of tension. Further, if a mydriatic is given the capsules are rendered taut; and if time is allowed for these capsules to get just so taut that they do not relax when the patient gazes close, but not so taut that they fail to relax when the 
other eye is pressed, and the fundus is at this stage flooded with a sufficiently strong light-stimulus to cause good contraction of the already moderately dilated pupil, the pupil-contraction thus produced takes place without causing any evident relaxation of the existing capsular tension, showing that tension of these capsules caused by the mydriatic is independent of the dilatation of the pupil which is also caused by the mydriatic. If, when the pupil is well dilated and the capsules are tense under the full influence of a mydriatic and cycloplegic such as cocain or homatropin, eserin is then instilled, in a very short time the capsules begin to relax and they then rapidly become extremely lax-far more lax than they ever were without the influence of a drug such as eserinthis occuring before contraction begins in the pupil which is still fully dilated by the mydriatic. When a stronger drug such as atropin is used, though longer time is required for the eserin action to begin to show itself by reduction of the capsular tension, even so this result occurs before the miotic begins to show its influence in diminishing the size of the dilated pupil. Tests made on other occasions which I have not quoted here confirmed that eserin acts on the capsular tension before it begins to act on the size of the pupil, when this eye has previously been subjected to the influence of a mydriatic."

(5) Ferree, C. E., Rand, G., and Wentworth, H. A. (Bryn Mawr, $\mathrm{Pa}$.).-The blind spot for achromatic and chromatic stimuli. Amer. Jl. of Ophthal., August, 1925.

(5) Ferree, Rand and Wentworth open their paper with a survey of the literature on this subject. This shows a great deal of disagreement in the results obtained, in work on the size of the blind spot. The authors therefore investigated the subject with special apparatus and their usual meticulous care. They found (1) that the blind spot for achromatic stimuli averages 7.6 per cent. larger on a white than a black field, using a black target in the first instance and a white in the second. This phenomenon is due to irradiation produced by the white object or white background. (2) The size of the blind spot for chromatic stimuli is greater than for achromatic stimuli, and depends on the colour of the surrounding field: on a grey background of the same brightness as the colour, the enlargement was $40-45$ per cent., on a black field 47-71 per cent., and on a white field 72-132 per cent. (3) The order of ranking in size is also affected by the background. From the largest to the smallest the order on a white field was green, blue, red, while for the grey and black fields, it was green, red, blue.

F. A. Williamson-Noble. 
(1) Sprague, White, and Kellog.-Disturbances of vision due to digitalis. Jl. of A mer. Med. Assoc., September 5, 1925.

(1) This is a report of seven cases which received an excessive dose of digitalis. In all but one case this was due to incorrect dosage by the physician in charge, or misunderstanding on the part of the patient. Sprague, White, and Kellog sum up as follows :

"Five patients complained of a defect of colour sensation; four had yellow vision, one red-yellow, and two green. All complained of decrease of visual acuity, and three said that they seemed to be looking through mist. Two had difficulty in focussing the eyes for reading, two had definite scotomas, and three had flickering before the eyes. In one instance the patient said that surrounding objects in sunlight appeared covered with snow.

"In two cases the visual disorders preceded the gastro-intestinal and cardiac effects; in two others, disturbances of the eye were associated with nausea and vomiting as the first toxic symptoms. Two patients with marked visual effects had no change in cardiac rate or rhythm, and one of these had striking xanthopsia without either nausea or cardiac effects.

"In three cases, extreme muscular weakness, described in digitalis intoxication, was a prominent feature. This, with the gastro-intestinal complaints, was considered by the patients of more serious importance than the eye symptoms; and it was therefore necessary to question them carefully to secure an adequate description of their visual disorders.

"Disturbances of vision resulting from the internal use of digitalis have been known at least from the time of Withering. Such disturbances have only rarely been described in the English literature, but have been carefully reported in German and French."

\section{A. F. MacCallan.}

(2) Mills, Lloyd (California).-Eyedness and handedness. Amer. Jl. of Ophthal., December, 1925.

(2) The dominance of the right or the left eye and greater facility of using the right or left hand are designated as "eyedness" and "handedness." Lloyd Mills has made an interesting investigation into these conditions and the following are some of his findings. One eye always posseses a greater sense of clarity or discrimination, even when both are alike in refraction. The right is usually the better. This forms part of a general bilateral asymmetry of function, so that in the right handed, the centre of 
gravity of the whole body is to the right. This causes one to walk, swim, or run to the right, in the absence of guiding marks. 'This asymmetry is probably of great advantage to mankind since it simplifies neuro-muscular control and inhibition. Eyedness determines handedness, the line of vision of the eye, chosen as the fixing eye, regulating the matter of dominance of the corresponding side of the body which it guards and controls. Signs of left handedness can be found in 20 per cent. of the population, frequently with a familial history. The figure indicates that sinistrality persists as a Mendelian recessive in spite of racial training to eradicate it. The characteristics of the non-master eye are, that it is cyclophoric, frequently hyperphoric, and that it diverges when a test object is brought closer than the convergence near-point. A useful object is the plane ophthalmoscopic mirror. This is held at a distance of two feet from the patient, who is asked to fix the hole in it. It is then steadily brought forward in the median line until one or other eye diverges. There are four groups of dextrals and sinistrals. (1) The pure dextral, right handed and right eyed, 76 per cent. of the population; (2) the pure sinistral, left handed and left eyed, 9.3 per cent.; (3) the crossed dextralright handed (usually by training), and left eyed, 13 per cent.; (4) the crossed sinistral, left handed and right eyed, 1.7 per cent. The characteristics of these groups are modified early in life by injuries or diseases which greatly reduce visual acuity in the master eye. After the pathways establishing ocular dominance are fully developed, mastery may persist, however, in spite of great loss of vision in the master eye. Conical cornea usually appears first in the non-master eye, i.e., in the eye which is on the weaker side of the body. Ocular mastery should be maintained with care in the correction of errors of refraction, particularly in myopia and anisometropia.

\section{F. A. Williamson-Noble.}

(3) Adler, Francis, and Landis, E. M. - The effect of miotics and mydriatics. Arch. of Ophthal., May, 1925.

(3) This investigation was undertaken by Adler and Landis on account of the conflicting results obtained by Wessely and by Seidel. The former holds that the increase in protein content of the aqueous which follows instillation of miotics is due to increased permeability of the capillary walls, the latter that it is due to direct stimulation of the ciliary epithelium. In their earlier experiments the investigators followed Seidel in estimating the amount of protein by means of the refractometer. This method, however, was useless as it was susceptible of a hundred per cent. error, and by using the "nephelometer" method-described in the text-the experimental error was cut down to 2 per cent. Certain precautions 
are necessary, e.g., the aqueous must always be withdrawn in the same amount and at a uniform rate, and the iris must not be damaged. The findings, in which the figures give the average of several experiments on different animais, were as follows : (1) Two drops of 1 per cent. eserin instilled in one eye at half-hour intervals, and aqueous withdrawn from both eyes half an hour later. The eye which had had the eserin showed a 44 per cent. increase of protein in the aqueous; (2) a similar experiment using atropin showed no effect; (3) a similar experiment in which atropin was followed by eserin showed no increase in the protein content, i.e., the effect of eserin was prevented by the previous use of atropin; (4) control experiment in which nothing was put in either eye, average difference 1.6 per cent. ; (5) pilocarpin used, no increase of protein ; (6).extirpation of one ciliary ganglion a month before-decrease of protein in the affected eye, 28 per cent. ; (7) effect of eserin on the denervated eye-protein in aqueous, 11.4 per cent. above that in unaffected eye, i.e., allowing for effect of extirpation of ganglion, total increase is $11.4+28.2=39.6$, a figure closely approximating to that found in experiment (1). The authors consider that these results are difficult to interpret, in view of the difference between the effect of removal of the ciliary ganglion and the instillation of atropin. They feel justified, however, in saying that eserin causes an increase in protein content by action on some other structure than the third nerve fibres running to the ciliary epithelium. Seidel's contention that the action of eserin is a proof of the secretory activity of the ciliary epithelium, is therefore not valid.

\section{F. A. Williamson-Noble.}

(4) Cazalis, Jean, neveu (Beziers).- On the usefulness of miotics in the treatment of superficial keratitis, simple or ulcerative. (De l'utilité des myotiques dans le traitement des kératites superficielles simples ou ulcéreuses.) La Clin. Ophtal., May, 1925.

(4) Cazalis in the course of a short article advising a more general employment of miotics in corneal disease after atropin has been disappointing in its effects, utters a caution about the use of miotics which seems worthy of special notice. "In old people, and especially in our southern climates, even in the complete absence of hypertension and of any appreciable participation of the iris in the inflammatory process, miotics have sometimes a tendency to produce a kind of tetany (tétanie) of the iris with posterior synechiae; these adhesions to the anterior capsule are not without disadvantage and by the screen which they interpose between the anterior chamber and the posterior media they ultimately bring about the risk of glaucoma or of sympathetic 
irritation." The author has never seen this complication in persons under 50 years of age.

ERnest Thomson.

(5) Ramsay, A. Maitland (St. Andrews). - The symptomatology of disturbances of the visual function. Glasgow Med. Jl., November, 1925.

(5) There are various ways of discussing the diseases of an organ. The usual way is the textbook way of describing the diseases with their symptoms. Another way is to take the various symptoms exhibited and to correlate them with the diseases. In this lecture delivered at the opening of the winter session of the James Mackenzie Institute for Clinical Research, St. Andrews, Ramsay adopts the last-named method and one feels that a critical, though doubtless non-specialist audience, must have been greatly interested. Ramsay says : "It has always been my endeavour to bridge over the gap between narrow specialism and general medicine, because I believe that no progress can be made until it is recognized that the principles of general physiology are sufficiently broad and deep to include every organ of the body. To emphasize specialism is a retrograde step. It is always the same physiological and pathological processes that are at work." Ramsay's students all know how well he succeeded in this endeavour, and in this lecture, presumably to a general medical audience, there is a large amount of mixed wisdom, that of the physician and the specialist, and the specialist no less than the general physician may well be able to profit by it.

Ernest Thomson.

(6) Ruata, Prof. Vittorio (Padua).-Nicotinism, nicotine amblyopia and the treatment of these conditions. (Considerations sur le nicotinisme, l'amblyopie nicotinique et leur traitement.) La Clin. Ophtal., January, 1925.

(6) To judge from Ruata's article tobacco poisoning must be a very serious trouble in the district in which he practises. Ruata says, in the first place, that tobacco-alcohol amblyopia ought to be called tobacco amblyopia because tobacco is really the determining agent. Alcohol is merely one of the aggravating agents, others being represented by overwork, poor diet, poor digestion, bad hygienic conditions and so on. In the second place, tobacco amblyopia should be considered as one of numerous symptoms of chronic tobacco poisoning, and as a symptom which is never primary but always preceded or accompanied by disorders of the cardio-vascular, digestive, and nervous systems. It represents an advanced and relatively serious stage of tobacco intoxication. Thirdly, the author seriously suggests that inveterate tobacco users 
should be treated in the same way as morphinomaniacs and be interned in private hospitals (maisons de santé, which perhaps even means asylums) in which they should be treated under strict supervision not only by deprivation of tobacco but in other ways calculated to eliminate the poison and to improve the general health. With regard to the treatment of the general condition, Ruata, having tried all the usual drugs such as strychnine, lecithins, bromides, valerian, etc., has had great success with a preparation which he says is well known in Italy, being prepared at the Zoja laboratory, Milan. This preparation which was introduced in 1906 by Professors Vanzetti and Piccinini is a formate of tetramethyl-ammonium. It is a cardio-tonic of the caffeine type, a myo- and neuro-tonic of the strychnine type and also has a hypercrinic action, that is, it stimulates all the secretory functions.

ERnest Thomson.

(7) Goadby, Sir K.-Latent sepsis. The Practitioner, November, 1924.

Cotton, H. A. (New Jersey).-Effect of chronic sepsis upon the central nervous system. The Practitioner, May, 1925.

(7) The many pathological eye conditions resulting from latent sepsis are known to ophthalmic surgeons, but the method by which the poison acts is not so well recognized. Goadby explains this in his article. He mentions that digestion of bacterial protein either by autolysis or by tissue enzymes may result in poisonous products. Chronic infection of the tonsils and gums (pyorrhoea), old persistent infection of the mucous membrane of the uterus, the urethra, and above all, the lining membrane of the large bowel in chronic constipation and intestinal sepsis, appear to fulfil all the conditions necessary to promote bacterial autolysis and diffusion of the resulting poisonous compounds. These poisonous protein substances, originating from bacterial autolysis, are not specific poisons; they may be produced from the protein of any bacterial species, and from their special nature produce no immunity response, nor antitoxin. Sub-infection, where the bacteria gaining entrance are dealt with promptly by the phagocytes, must not be confused with latent infection, where the bacteria are out of reach of phagocytic activity. It is impossible to estimate the far-reaching effects of small but persistent foci of latent sepsis. It is not improbable-more, it is possible-that the insidious onset of arterio-sclerosis and the first breakdown of the kidney cells in chronic nephritis are but the sequels to absonption of unspecified bacterial poisons generated in sequestered and undetected places.

Cotton believes that there are two forms of toxaemia resulting from intestinal stasis.. One type is the result of infectious processes 
in the walls of the colon. The other form of intestinal stasis is due to generation of toxic products from the retained residue of the digestive processes. He is convinced that toxaemia is the cause of all the so-called functional psychoses, and he has successfully treated by detoxication 86 per cent. of the 1,600 cases which have been under his care. He believes that the principal factor is cerebral toxaemia, the result of chronic sepsis located in the teeth, tonsils, gastro-intestinal tract, and genito-urinary system. Proof is found in the fact that when such foci of chronic sepsis are eliminated early in the course of the disease, the mental symptoms disappear.

\section{A. F. MacCallan.}

(8) Edeskuty, O.-Primary Necrosis of the Iris. (Ueber primäre Irisnekrose.) Zeitschr. f. Augenheilk., Vol. LV, p. 38, 1925.

(8) Edeskuty describes an interesting case of a shoemaker, aged 61 years, who, without any apparent cause, suddenly developed a severe inflammation in the left eye accompanied by a violent headache confined to the same side of the head and temple. After the first day vision completely disappeared from the eye. The cornea was dull, and the iris swollen and discoloured, and a considerable deposit of "k. p." was evident. The trouble progressed rapidly, and a fibro-purulent discharge filled the anterior chamber, leading to an increase of tension and much pain. An anterior sclerotomy was therefore performed, but this giving only temporary relief, the eye was finally enucleated.

Histological examination showed three areas of necrosis in the cornea, while the whole of the iris substance was in an advanced necrotic condition. Edeskuty considers that the microscopic findings were identical with those described by Meller (Zeitschr. f. Augenheilk., Vols. XLIII and L) as occurring in cases of herpes, and such an explanation, in his opinion, would adequately account for the similar condition in the cornea : an atypical case of herpes with unusually severe ocular complications.

W. S. Duke-Elder.

(9) Comberg, W., and Stoewer, E. (Berlin).-The mechanism of raised intra-ocular pressure on muscular contraction and its clinical importance. (Die Augendrucksteigerunde Wirkung verschiedener Muskelaktionen und ihre Bedeutung fur klinische Verhaltnisse.) Zeitschr. f. Augenheilk., Vol. LVIII, p. 93, 1925.

(9) In the German literature there are two views on the mechanism of the raised intraocular pressure which accompanies contraction of the orbital musculature : the one (Levinsohn, 1910), that the larger part of the reaction is due rather to incidental 
causes such as vaso-motor disturbances, and that the action of the muscles themselves is without large practical importance; the other (Lederer and Wessely), that the orbital muscles play the preponderating part. Comberg and Stoewer claim to have substantiated the latter view in a series of experiments whereby the intraocular pressure, as taken by the Schiötz tonometer, was compared when the two influences were to some extent dissociated.

A series of comparative measurements of the intraocular pressure and general blood pressure (sphygmomanometer on arm) were taken on compression of the chest and thorax (Valsalva's experiment). Under these conditions the systolic/diastolic blood pressure rose from $90 / 120$ to $120 / 160 \mathrm{~mm}$. $\mathrm{Hg}$, and the intraocular pressure from 18 to $30 \mathrm{~mm}$. $\mathrm{Hg}$ (Schiötz); the whole of this rise of pressure is presumably circulatory in origin and it came on slowly and established itself gradually. Another series of experiments in which the intraocular pressure was taken on forcibly closing the lids showed a much higher rise--from 18 to $65 \mathrm{~mm}$. Hg-and one which came on suddenly and disappeared immediately on stopping the blepharospasm; this effect is presumably largely due to the action of the muscles themselves.

Experiments were further done while the lids were thrown into voluntary spasm as in the act of closing while being held open by retractors. Here again a comparable rise of intraocular pressure was obtained, which the authors ascribe to the pressure of the pars orbicularis on the globe. No pattern of retractors could be found which were able to eliminate this effect, but it could be completely abolished (by paralysing the muscle) with an injection of novocain.

The clinical interest the authors attach to these experiments lies in the light they throw on the pressure conditions obtaining in an operation as for extraction of cataract. A series of experiments were done wherein the intraocular pressure was taken when the same amount of pressure was applied to the eye by a spoon as they conceived the average operator applies it to the cornea in the expulsion of the lens. The intraocular pressure rose from 18 to $30 \mathrm{~mm}$. Hg. Since this occurred in the intact eye, the rise of pressure that takes place in an operation in the open eye is presumably less, and experience shows that under this pressure vitreous is sometimes lost. This complication can therefore happen on the application of pressures less than those which are produced by spasm of the lids when the most efficient retractors obtainable are in use, or which are produced by a general rise of systemic blood pressure. Under these conditions the operator may reasonably be exonerated for the loss of vitreous during an extraction, the whole blame of which may be due to the muscular action of the patient. In all operations the patient should be 
instructed to avoid this muscular action, and moreover, not to strain in any way, but to lie lax, breathing regularly and deeply; and in any case where the indications point to these instructions as not likely to be carried out, a preliminary injection of novocain provides the only absolute safeguard against accident.

$$
\text { W. S. Duke-Elder. }
$$

\section{(ro) Kyrieleis, Werner (Würzburg)._-On unusual manifestations of pulsation in the vessels of the human fundus. (Über seltene Pulsationserscheinungen an der Gefässen der men- schlichen Augenhintergrunde.) Arch. f. Augenheilk., Vol. XCVII, December, 1925.}

(10) As far back as 1855 Donders established that the retinal venous pulsation is an altogether physiological occurrence in the normal eye. Although by means of Gullstrand's binocular ophthalmoscope Kümmell has been able to observe it in practically every eye examined the usual uniocular ophthalmoscopy does not reveal it. The normal venous pulsation is centripetal. In view of the numerous anastomoses of the ophthalmic vein with the veins of the face, the pulsation cannot be explained mechanically as a periodical obstruction to the passage of blood. But that under exceptional conditions venous pulsation could result from mechanical obstruction and be observed by ordinary ophthalmoscopy is shown by Kyrieleis in the following case :

An unconscious man suffering from comminuted fracture of the skull was examined ophthalmoscopically two days after the accident. The right eye was both externally and internally normal. The left eye showed abrasions, burns and extravasations of blood in both lids, ptosis, mydriasis and immobility of pupil and slight exophthalmos. The fundus showed slight but unmistakable pulsation of the retinal veins; it was synchronous with the radial pulse and immediately presystolic. The optic disc was sharply defined. The day after the condition was still unchanged. At the last examination which had to be done three weeks later no pulsation could be made out and exophthalmos had practically gone. The author thinks that the explanation of this phenomenon is to be sought solely. in a mechanical obstruction to the outflow of blood and that, from the findings at the first examination, its true relation to the cardiac cycle, and its course, it is certain that it was not a case of pulsating exophthalmos. In all probability there was an extravasation of blood behind the globe compressing the venous outlet near the place where the central vessels leave the optic nerve and where the anastomoses with the ophthalmic vein are not yet effective. 
The second unusual case is one of pulsation of a choroidal artery in a highly myopic eye which had been operated on after the method of Fukala. As the result of secondary glaucoma there was almost complete atrophy of the iris whose remnants were adherent to the cornea at the periphery. The vitreous and fundus showed very advanced myopic degenerative changes. The choroidal vessels were strikingly well seen. One choroidal artery, springing with a sharp kink from the medial border of the ringshaped posterior staphyloma and arching upwards, showed marked pulsation. There was no pulsation whatever to be recognized in the remaining choroidal vessels. $T .=55 \mathrm{~mm}$. $\mathrm{Hg}$ (Schiötz), B.P. 90/60 (Riva-Rocci).

Although an increase of intraocular pressure closely approximating the diastolic blood pressure naturally favours the spontaneously visible pulsation, the author thinks that it cannot be the sole factor in the given case as otherwise the pulsation should have been visible in the other choroidal vessels as well. The other factor is the mechanical obstruction due to the sharp kink that the vessel makes at the border of the staphyloma where it disappears into the choroid. There is a diagram in the text to illustrate this condition.

D. V. GIRI.

(I I) Ferree, C. E., and Rand, G. (Bryn Mawr, Pa.), and Monroe, M. M. (Philadelphia).-Studies in perimetry. I. Preliminary work on a diagnostic scale for the form field. Amer. $\mathrm{Jl}$. of Ophthal., February, 1926.

(11) Feree, Rand and Monroe have investigated the fields of 200 individuals with normal fundi in order to determine the range of variation which may be expected in non-pathological cases. The ideal method of comparison would be to measure the total area of the field of vision as plotted on a standard chart. Certain practical difficulties occur in this, and an almost equally good result is obtained by taking the mean of the extent of the field in degrees in the eight cardinal directions. The investigations were made with Ferree and Rand's special perimeter using a white object, subtending a visual angle of $1^{\circ}$, on a black background. In general, it was found that emmetropes and hypermetropes have the wider fields and myopes, the narrower. There was only one case whose average breadth of field was less than $60^{\circ}$. It may therefore be stated that any field must be regarded as suspicious, if its average breadth is less than this amount. It was also found that out of 125 cases of emmetropia only six showed an average breadth of less than $64^{\circ}$ so that $64^{\circ}$ should be the critical figure in such cases-in myopes or presbyopes, it is about $62^{\circ}$. The shape of 
the field is naturally of more importance in the diagnosis of pathological changes than the size, but the present paper is concerned only with the latter factor. The authors note that "the amount of contraction of field produced by a defect of refraction in a non-pathologic eye may be as great, or even greater, than that produced by an incipient pathologic condition in an emmetropic eye."

\section{F. A. Williamson-Noble.}

(12) Lagleyze, M.-Double intraocular foreign body. (Doble cuerpo extraño endocular.) Arch. de Oftal. de Buenos Aires, Vol. I, p. 70, December, 1925.

(12) Lagleyze records a case of two foreign bodies in the eye, which he considers interesting as showing the advisability of attempting removal in all such cases before it is rendered difficult or impossible by the formation of fibrous encapsuling tissue.

The patient came to the clinic with pain, photophobia, and pericorneal injection, and showed a corneal perforating scar and the formation of a hyphaema. X-rays revealed a foreign body in the eye, which was found to be magnetizable and was thus removed. The eye thereafter quietened down, but three months later he returned with a renewal of symptoms. An accidental radiographic examination (undertaken for other purposes) revealed a second foreign body which had escaped notice in the first examination, and ophthalmoscopic examination showed a yellow mass lying in the vitreous just behind the ciliary body at the extreme periphery. This was also magnetizable but all attempts with the magnet failed to remove it. As all vision had disappeared, the tension was raised, and the pain considerable, the eye was enucleated. A piece of metal was found lying deeply embedded in fibrous tissue, with which was associated a shallow detachment of the retina.

W. S. Duke-Elder.

(13) Thiel, R. (Berlin)- -Slit-lamp microscopy of the eye in ultraviolet light. (Ein Beitrag zur Spaltlampenmikroskopie des Auges im ultravioletten Licht.) Zeitschr. f. Augenheilk., Vol. LVIII, p. 86, 1925.

(13) Thiel has studied the microscopy of the living eye as seen through the slit-lamp by the aid of ultra-violet light, the appearances being rendered visible by means of fluorescence. He uses a carbon arc fitted on a slit-lamp whose optical system is of quartz, and induces fluorescence by giving the patient 2 to $3 \mathrm{gms}$. of sodium fluorescine in tea or coffee 30 or 40 minutes before the examination. 
As with all red-free light the blood-vessels appear black, and around them a narrow circumscribed space is evident which is clearly fluorescent, appearing as a greenish-yellow line. This represents the perivascular lymph sheaths, and when the vessels are engorged, as in inflammatory states of the iris, this completely disappears. The fluorescine quickly finds its way into the aqueous, which fluoresces. The normal cornea shows no characteristic appearance, but folds in Descemet's membrane show up clearly in a light violet colour in the reflected fluorescent light from the lens. The lens cortex fluoresces as a pale yellow and ghostly green, while the nucleus appears yellow-grey. Shagreen of the lens is well recognized. Capsular opacities, inflammatory deposits, subcapsular vacuoles, etc., are well shown up : pigment on the anterior capsule, posterior synechiae, and the remains of past iritis appear as a milky blue, and the presence of minute opacities in the anterior cortex are much more readily detectable than by natural light and throw dark needles of shadow back into the body of the lens. Nuclear opacities show slight or no fluorescence, and therefore the opaque parts of the lens appear as blue-violet islands in the yellow-green of the fluorescent light ; opacities in the anterior cortex show the same light violet reflex as the adjacent iris; opacities in the posterior cortex appear as dull reddish-grey, and fluid vacuoles and lacunae as a faint blue.

The swelling and degeneration of the lens fibres run parallel with a decrease in fluorescence, and in this way the development of a cataract can be closely followed, particularly the forms following needling and injury. For the same reason, an after-cataract does not fluoresce. A definite indication of the extent of lenticular damage after trauma is thus offered, or of the efficiency of a discission. Thiel also asserts that he has by this means substantiated the claim of Elschnig (Klin. Monatsbl. f. Augenheilk., Vol. XLIX, p. 444, 1911) that there is a considerable formation of new lens fibres after an extraction due to proliferation of the epithelial remnants, and disproved the statement of Greef (Path. Anat. d. Auges. in Orth's. Path. Anat., p. 483, 1902-06) that the whole of an after-cataract is due to incomplete removal of the cortex at the time of operation.

One of the advantages claimed for the method is that in conditions where one cannot see into the eye with ordinary light, the fluorescent light is appreciable; much information can thus be obtained regarding the inner structures in cases where the cornea is so opaque or the anterior chamber so filled with exudate that other methods of investigation are of little use.

W. S. Duke-Elder. 
(14) Gourfein, D. (Geneva).-Diocain in ophthalmology. (La diocaine en ophtalmologie.) Rev. gén. d'Ophtal., January, 1926.

(14) Gourfein, while paying tribute to the many virtues of cocain, apparently maintains that diocain is for all purposes better. He gives a list of the disadvantages of cocain namely, the effect on the corneal epithelium and on the pupil and accommodation, and its toxicity. Diocain on the other hand, gives rise to no "unpleasant sensation," is much less toxic than cocain, can be sterilized every day without losing its efficacy, produces when instilled a complete and rapid anaesthesia, and, when injected subconjunctivally, causes no hyperaemia or corneal lesions. It can be instilled in large quantities without causing trouble and without alteration of the corneal epithelium. It does not affect the accommodation nor the tension, nor does it produce mydriasis. According to the author's own statement he has studied the drug clinically only and is not speaking of its toxicity "from the physiological standpoint." He refers to the work of his "young colleagues," Koby and Lussi. Now, if readers will refer to the abstract of Koby's article on page 600 of the British Journal of OpHTHALMOLOGY for 1925, they will find certain disadvantages of diocain there stated, though they are not given as disadvantages compared with cocain but compared with holocain of which diocain is a derivative. (1) It is precipitated if the glass vessel containing it contains alkali and it has to be dissolved in boric acid ; (2) instillation "up to 1 per cent." is pain!ess, leaving it to be inferred that the drug is not, as stated by Gourfein, free of painful effect when used in strengths higher than 1 per cent. Yet Gourfein recommends 2 to 5 per cent. solutions. (3) It is evidently fairly toxic since the author suggests that for repeated instillations the strength should not exceed two to three per thousand. There are certainly points of difference in the views of Gourfein and of Koby, but it is to be noted that Gourfein emphatically states that clinically he has not noticed the least toxic effect either in children or adults among over 300 cases in which the drug was either instilled or injected.

Ernest Thomson.

(I5) Meller, J.-Spontaneous bleeding in atrophic eyes. (Ueber spontane Blutungen in atrophischen Augen.) Zeitschr.f. Augenheilk., Vol. LVII, p. 131, November, 1925.

(15) In a long and detailed paper illustrated by pertinent cases, Meller discusses the question of the aetiology and effects of the spontaneous haemorrhages that sometimes occur in atrophic eyes. 
He differentiates three types :

(1) Haemorrhages from the organized tissue covering of the ciliary body and vitreous which is formed during the course of the primary inflammatory disease (Schwartenblutungen). The new vessels in this tissue are easily liable to be ruptured, either from the mere shrinkage of the tissue itself, dragging upon them or occluding them locally, or from various trifling causes (traumatic, etc.), such as would leave the normal eye unaffected. (2) Spontaneous sub-choroidal haemorrhages, which occur usually in eyes in which the primary trouble involved a prolonged state of hypertension. The main element in the occurrence of these is suggested as a weakening of the vorticose veins and the choroidal vessels supplying them by the mechanical dilatation of the eyeball during the period of raised tension and its shrinkage after that tension has died down. These two types may occur simultaneously and independently of each other. (3) Haemorrhages in the tissues of the eye itself ; this occurs more rarely. In the paper two illustrative cases are given, in one of which such a haemorrhage occurred in the pupillary part of the iris, and in the other it was due to a tear in the retina caused by contraction of organized exudative tissue (schwartenzug).

Two effects of these haemorrhages are discussed:

(1) They produce a rise in pressure-a purely volume effect. This is usually of little consequence, the shrunken eyes often remaining still more hypotonic than normal after the haemorrhage. (2) An inflammation which is often set up after the haemorrhage, independent of the inflammatory infiltrations inside the eye, is of more importance. This is probably responsible for the sudden inflammatory attacks which often occur in atrophic eyes which have long been quiet, an occurrence which often necessitates enucleation. The new haemorrhages from the old inflammatory tissue produce an inflammatory reaction with a histologically recognizable infiltration round about it, due to changes taking place in the composition of the extravasated blood after it has remained for some time. A repetition of this bleeding, with its consequent reaction, brings on a sudden severe disturbance of an anaphylactic nature. This process occurring in the sub-choroidal vessels Meller regards as being the cause of "pseudo-sympathetic choroiditis"; and he describes several cases wherein a similar delayed and severe "sympathetic" inflammation in such atrophic eyes could be definitely associated with recurrent reaction-producing haemorrhages. The author considers that these facts should weigh in the consideration of the advisability of enucleating eyes of this atrophic type.

IV. S. Duke-Eldir. 